\title{
13
}

\section{Alternative Routes}

\subsection{Alternative Routes Through the BMT}

This book is designed to support you to work through the ten building blocks, which are grouped into the Definition, Design and Result Stages, from left to right and top to bottom. The underlying idea is to develop a business model from scratch by following each step in the BMT system.

From our experience you can easily spend a couple of weeks doing this (but it could take longer depending on the nature of your idea). Not because you spend every hour of every day working on it (although you can do so), but because you also have to take the time to let your business model-tobe sink in. Crucial to the process is looking at your BMT from different angles, getting people to give you constructive feedback on your idea, and, last but not least, getting distance from it and coming back to it with fresh eyes. Taking your BMT through several iterations will help to improve your business model idea step by step.

And remember, you are rarely unique. Somewhere, someone or a group of people is working on the same idea in the same way, or maybe just a little differently. Find out where these people are, contact them, and discuss your ideas. Share your knowledge - on your own, you may be faster, but together you can achieve much more. 


\section{TIP}

As we said before, the BMT is by no means the only canvas available. For further inspiration, take a look at www.designabetterbusiness.tools/search?q= canvas. On this site, you will find a large number of other canvasses that may be useful. But be careful not to get waylaid by this search. Constantly ask yourself if the principles underlying a certain tool will help lead to the creation of a sustainable business model.

That said there are many other possible routes through the BMT, and next we outline five possible alternatives: (1) Idea-driven, (2) Propositiondriven, (3) Network-driven, (4) Impact-driven, and (5) Competence-driven. To provide you with some inspiration, we will briefly elaborate on each of these five routes with examples. Please note that the texts used for the examples presented are taken almost verbatim from the websites of the various institutions and companies bar slight modifications to improve the readability of the texts. This is intentional because these examples were selected to demonstrate how organizations apply a particular approach in practice. In addition to including the primary source for the example, we also looked for a matching YouTube clip that explains the project (Table 13.1).

Table 13.1 Alternative ways to use or routes through the BMT

\begin{tabular}{|c|c|c|}
\hline Approach & $\begin{array}{l}\text { Starting Building } \\
\text { Block }\end{array}$ & Comments \\
\hline Idea-driven & $\begin{array}{l}\text { \#1 Motive and } \\
\text { Context }\end{array}$ & $\begin{array}{l}\text { Start from a 'great' idea you have identified to solve a certain } \\
\text { issue, around which you further develop the business model. }\end{array}$ \\
\hline Proposition-driven & \#3 Proposition & $\begin{array}{l}\text { The value that you want to create for a specific target group is } \\
\text { paramount here in the development of your business model. }\end{array}$ \\
\hline Network-driven & \#5 Parties & $\begin{array}{l}\text { The network of parties that already exists is the basis for the } \\
\text { further development of the business model. }\end{array}$ \\
\hline Impact-driven & \#9 Impact & $\begin{array}{l}\text { The impact that you want to achieve is key for the develop- } \\
\text { ment of your business model. }\end{array}$ \\
\hline Competence-driven & \#7 Core Activities & $\begin{array}{l}\text { The things you are really good at are central in the develop- } \\
\text { ment of your business model. }\end{array}$ \\
\hline
\end{tabular}

\subsection{Idea-Driven}

The idea-driven approach enables you to work through the ten building blocks step by step from top to bottom and left to right-reflecting the format of this book. Starting with a great idea you have identified to solve 


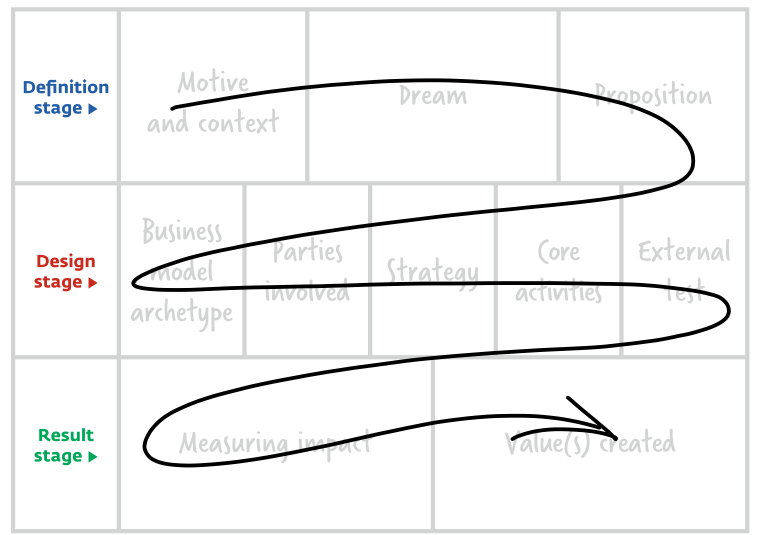

Fig. 13.1 Idea-driven

a certain issue you can use the BMT to systematically go through all the steps to develop a new business model (Fig. 13.1).

\section{Case Study: Seaweed for packaging-Ooho (United Kingdom)}

Ooho is a company that has developed the Notpla technology, a material made from seaweed and plants. The material is used for packaging which is edible or biodegrades in four to six weeks. The company is currently building an onsite manufacturing machine to use the Notpla technology for the production of sustainable packaging. From 2021 onwards, the company will lease these manufacturing machines to companies that produce single-use plastics such as nets or sachets. The home-compostable Notpla contributes to a plastic-free world without microplastics.

Website: www.notpla.com

Youtube: www.youtube.com/watch?v=Pj6Q-YCcA3s

\subsection{Proposition-Driven}

The proposition-driven approach is based on the value that you want to create for a specific target group. The revision of an existing idea, or even an entire business model, is central (Fig. 13.2). 


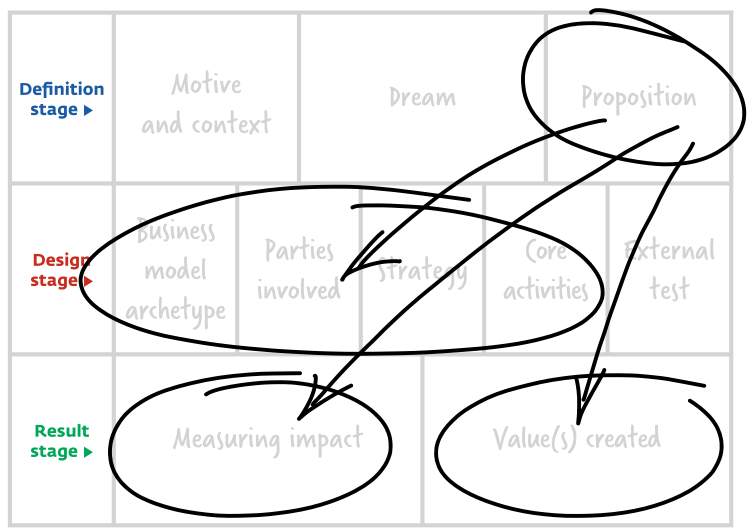

Fig. 13.2 Proposition-driven

\section{Case Study: Recycling sportswear-Adidas and Stuffstr (United Kingdom)}

Adidas has launched a new recycling initiative in the UK, entitled Infinite Play, in which customers are incentivized to pass on their old sportswear instead of sending it to landfill. Social enterprise Stuffstr, the London Waste and Recycling Board (LWARB), and QSA Partners organize the service which allows customers to trade worn or unused Adidas gear for e-gift cards and Adidas Creators Club loyalty points. By using the Adidas app, the Stuffstr system allows customers to sell back their unwanted clothing for store credit, regardless of condition, creating a closed-loop solution for the fashion industry.

Website: www.stuffstr.com

Youtube: www.youtube.com/watch?v=2LUkcfWE4UQ

\subsection{Network-Driven}

The starting point of the network-driven approach is a network of parties that want to work together on sustainable innovation with their different (but complementary) core competencies. Here the function of the BMT is to gain insight into the context and the (intended) network associated with it while being mindful of the fact that networks are ubiquitous: many companies want or need to work together.

You develop a BMT for your ideal network. To do so in the Design Stage, you can start with Building Block \#5-Parties. Logical as this may sound, it may not be enough. Presumably, you want to involve your existing partners in your business model, but also attract new partners. You may need 


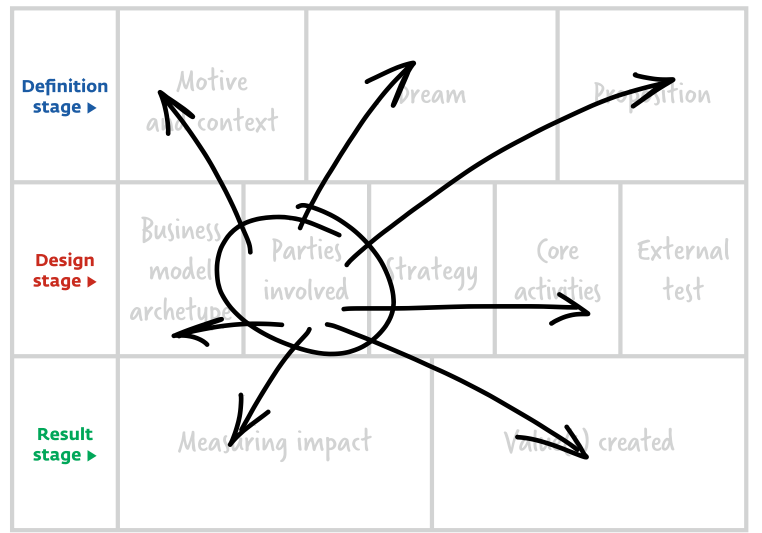

Fig. 13.3 Network-driven

to use an additional instrument to find out what competencies are present in your network and what gaps you need to fill. It may, therefore, be useful to perform a separate network analysis if you adopt this route through the BMT (Fig. 13.3).

\section{Case Study: Net-Works}

The central theme of Net-Works is making beautiful things out of waste. Net-Works allows residents to collect discarded fishing nets that cause many problems in the marine ecosystem. They are then sold back through a global supply chain, giving these devastating, broken fishing nets a second life as beautiful, durable carpet tiles. The Net-Works programme was driven by a need to do business in an inclusive manner. An inclusive company is a profitable company that creates jobs in low-income communities, either directly or by including a development group in the value chain. Working closely together, stakeholders create a robust business solution that has a positive long-term impact on fresh and saltwater ecosystems, while at the same time providing financial opportunities for some of the world's poorest people. It has a socio-economic and an environmental impact. The Net-Works initiative, which emerged from an unlikely partnership, shows that when the business world, environmental organizations, and communities innovate together, positive and sustainable change can result. To date, the programme has collected 66,680 kilograms of discarded fishing nets and generated enough income for 230,667 meals for local families.

Website(s): www.net-works.com

www.interface.com/APAC/en-AU/about/mission/Net-Works-en_AU

Youtube: www.youtube.com/watch?v=DX6Uidpg3VM\&t=5s 


\subsection{Impact-Driven}

The main focus of the impact-driven approach through the BMT is on creating a certain impact. The function of the BMT will therefore support the development of a business model based on a predetermined idea about impact (Fig. 13.4).

\section{Case Study: Dopper}

Crystal clear water. In every ocean, from every tap. Isn't that what we all want? Bad news. Every year, 8 million tons of plastic waste ends up in our oceans. This plastic waste does not degrade. Ever. It just breaks down into smaller and smaller pieces. Every minute, a massive amount of plastic ends up in our oceans. And in that very same minute, one million single-use plastic water bottles are sold. Meet the reusable bottle that eliminates the need for single-use water bottles. With a Dopper bottle, you have no excuse to buy single-use water bottles. Doppers are produced sustainably. And yes, most Doppers are made of plastic. But this plastic can be used again and again. Our bottles are available in a variety of materials, colours, and models. And when you don't want it anymore, it can be fully recycled! So whatever style you have, and whatever way you drink your water, there is a Dopper to suit you. Our bottles make the difference. Each bottle sold contributes to our projects, from education programmes and research to inspirational campaigns. What do we do? We inspire. Our worldwide campaigns are spreading the message to stop plastic pollution by encouraging drinking water from the tap. And we are creating, step by step, a movement of change-makers.

Website: www.dopper.com

Youtube: www.youtube.com/watch?v=EUrJECVdw8Y

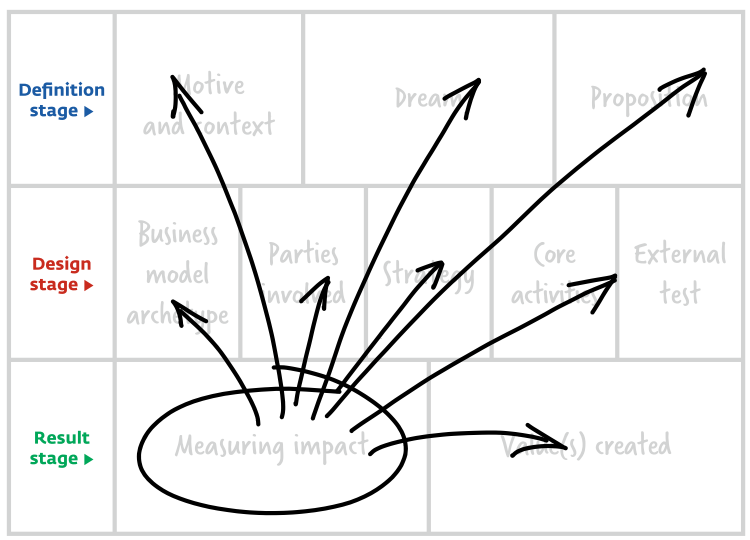

Fig. 13.4 Impact-driven 


\subsection{Competence-Driven}

In the competence-driven approaches available, core activities are key. What can be organized with the already developed core activities in the pursuit of sustainability? Here the function of the BMT is to develop new business models from an existing core activity (Fig. 13.5).

\section{Case Study: Aquafil \& Tarkett}

Paris, France and Waalwijk, The Netherlands, 21 November 2019-today. Tarkett announces that it is closing the loop on commercial carpet tiles in Europe thanks to a pioneering partnership with Aquafil. This is the result of an intensive collaboration over recent years, going beyond the traditional customer and supplier relationships. Today, the two companies present this significant step towards a circular economy at Tarkett's carpet tile facility in Waalwijk, The Netherlands. Its unique recycling centre creates two streams of materials that can be recycled and transformed into high-quality resources for new products. Tarkett has developed breakthrough technology at its Waalwijk facility. It is now able to separate the two principal components of carpet tiles-yarn and backing-while retaining more than $95 \%$ yarn purity.

'Technological innovation now makes it possible to multiply the life cycles of building materials. Together with Aquafil, we are accelerating our circular economy journey and leading our industry's progress in carpet recycling', says Fabrice Barthélemy, Tarkett's CEO. 'This is a fundamental step forward in maximizing the value of materials and preventing carpet tiles from being incinerated or sent to landfill. Truly closing the loop on flooring is a key driver of Tarkett's strategy to preserve natural resources and protect the environment'.

Giulio Bonazzi, Aquafil's CEO, comments: 'We are delighted to help Tarkett with the last mile of its journey to close the loop on carpet tile production. We must urgently transform the way products are designed, produced, and

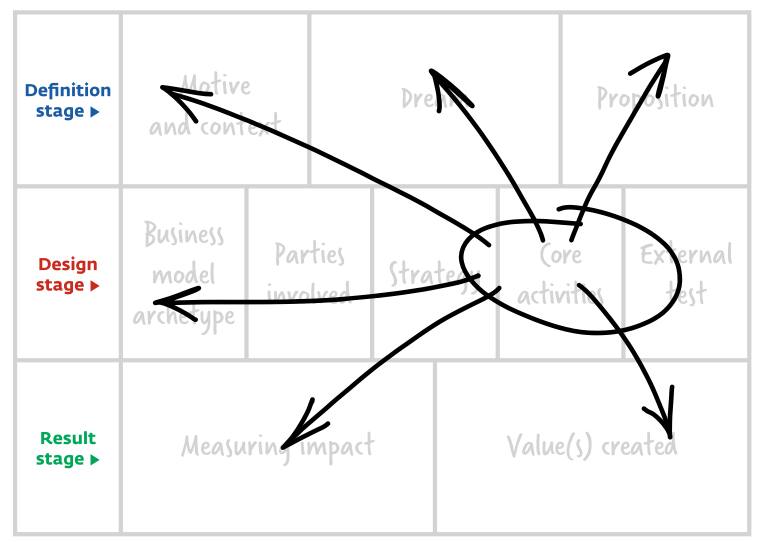

Fig. 13.5 Competence-driven 
consumed. Through our collaboration with Tarkett, we will strengthen our commitment to realizing this vision by increasing the reutilization of yarns and helping to design out waste'.

Website: www.aquafil.com/newsmedia/tarkett-and-aquafil-close-the-loopon-carpet-tiles-a-key-step-towards-circular-economy

Youtube: www.youtube.com/watch?v=uMqVZqmTQI0

\subsection{What Route Do You Take?}

Do the five routes through the BMT cover all possible routes? No, of course not. Think of the BMT as a box of building blocks for adults from which an endless number of combinations can be made. Ultimately, it is important for all users of the BMT-students, entrepreneurs, and intrapreneurs alike- to determine the most suitable approach or route through the BMT based on your own context and situation. If, for whatever reason, certain building blocks are particularly challenging, additional tools may be required to crystallize that part of your business model.

This point is illustrated by the fact that each of the individual building blocks can themselves be expanded on further. Take, for example, Building Block \#2-Dream, and consider using tools and frameworks that are available to support working out your venture's Mission and Vision. Or take Building Block \#9-Impact, about which there is still so much more to say, including regarding impact assessment. If you explore impact assessment in greater detail you will soon find yourself in a lively discussion involving both practitioners and academics, each proposing various frameworks and tools. This also applies to developing an understanding of networks (Building Block \#5-Parties). Since there are already so many tools available, we have intentionally not elaborated deeply on the theoretical debates in this publication, because we primarily wanted to focus on practice. Our key concern is that you look at these existing tools while asking yourself how they contribute to sustainability, circularity, and inclusivity (see Chapter 1-Speaking of Transition).

\section{Using a Modified PDCA Cycle}

That said, there is also something to be said for creating a modified Plan-DoCheck-Act/Adjust (PDCA) cycle (also known as the Deming Circle or the Shewhart Cycle) and using it to work your business model idea. Originally, 
the PDCA approach stems from the world of quality management. However, the four main steps, (1) Plan, (2) Do, (3) Check, (4) Adjust, can also be applied in the BMT context because the content of these four steps is empty. It is the user's task to operationalize these steps by using, among other things, the earlier-introduced principles, choices regarding the three types of business model, and elaborating on the impact you would like to create with your business model.

Open Access This chapter is licensed under the terms of the Creative Commons Attribution 4.0 International License (http://creativecommons.org/licenses/by/4.0/), which permits use, sharing, adaptation, distribution and reproduction in any medium or format, as long as you give appropriate credit to the original author(s) and the source, provide a link to the Creative Commons license and indicate if changes were made.

The images or other third party material in this chapter are included in the chapter's Creative Commons license, unless indicated otherwise in a credit line to the material. If material is not included in the chapter's Creative Commons license and your intended use is not permitted by statutory regulation or exceeds the permitted use, you will need to obtain permission directly from the copyright holder. 